\title{
Sonlu Elemanlar Yöntemi ve Hassasiyet Analizi ile İki Fazlı Yumuşak Dokuların Malzeme Özelliklerinin Tayini
}

\author{
M. Kerem ÜN*1 \\ ${ }^{1}$ Çukurova Üniversitesi, Mühendislik Fakültesi, Biyomedikal Mühendisliği Bölümü, Adana
}

Geliș tarihi: 07.09.2018

Kabul tarihi: 27.03.2019

$\ddot{O} z$

İki fazlı yumuşak dokuların malzeme özellikleri bu dokuların işlevlerini yerine getirmeleri açısından önemlidir. Bu makalede, iki fazlı dokuların elastik sabitlerinin ve hidrolik geçirgenliğinin, deneysel veriler, sonlu elemanlar yöntemi ve optimizasyon ile nasıl belirlenebileceği gösterilmiştir. Dokuların bünye denklemlerini içeren iki fazlı teori ile birlikte optimizasyon algoritmasının matematiksel formülasyonu tarif edilmiştir. Bu algoritmada anahtar rol oynayan ve malzeme özelliklerini güncellemek için yapılan hassasiyet analizi ayrıntılarıyla açıklanmıştır. Optimizasyon algoritması, yanal kısıtlı ve yanal kısıtsız sıkıştırma deneyi konfigürasyonları üstünde örneklendirilmiștir. Algoritmanın, lineer elastik katı fazlı bir dokuda Young modülü ve hidrolik geçirgenliğin, deneysel veri sayısı ve niteliğine de bağlı olarak görece az sayıda malzeme özelliği güncellemesiyle gerçek değerlerine yakınsamalarını sağladığı gözlemlenmiştir.

Anahtar Kelimeler: İki fazlı doku, Eklem kıkırdağı, Sonlu elemanlar, Malzeme özellikleri, Optimizasyon

\section{Determination of Material Properties of Biphasic Tissues Using Finite Element Method and Sensitivity Analysis}

\begin{abstract}
The material properties of biphasic tissues are important for these tissues to fulfill their function. In this paper, it is presented how the elastic constants and hydraulic permeability of biphasic tissues can be determined using experimental data, finite element method and optimization. The biphasic theory, containing the constitutive law of the tissues, together with the mathematical formulation of the optimization algorithm is described. Sensitivity analysis, which plays a key role in this algorithm and is utilized to update the material properties, is explained in detail. The optimization algorithm is exemplified with confined compression and unconfined compression experimental configurations. It has been observed that the algorithm, depending also on the number and quality of the experimental data, can make the Young's modulus and hydraulic permeability values converge to their actual values with a relatively small number of material updates in case of a linear elastic solid phase.
\end{abstract}

Keywords: Biphasic tissue, Articular cartilage, Finite element, Material properties, Optimization

*Sorumlu yazar (Corresponding author): M. Kerem ÜN, keremun@cu.edu.tr* 


\section{GíRiș}

Sonlu elemanlar yöntemi (SEY), mühendislik ve bilimde kısmi diferansiyel denklemlerle (KDD) tarif edilen olguları (deformasyon, isı transferi, elektrik alanı v.s.), sürekli ortamlar ("continuum") üzerinde modellemede kullanılan en önemli problem çözme aracı haline gelmiştir. Bilgisayar teknolojisindeki ilerlemeyle, SEY ile çözülebilecek problemlerin karmaşıklık düzeyi her geçen gün artmaktadır. SEY'nin sonradan ortaya çıkan bir başka kullanım alanı da, elektromanyetik, mekanik veya termal olsun, bir ortamin malzeme özelliklerinin belirlenmesidir. $\mathrm{Bu}$ uygulamada, deneysel veriyi teorik veriye uydurma, yani deney ve teori arasındaki hatanın en aza indirilmesi söz konusudur. Diğer bir deyişle, malzeme özelliği belirleme, aslen bir optimizasyon problemidir.

Analitik çözümler, tipik olarak, problem geometrisinin dikdörtgen bir kutu, bir silindir veya bir küre gibi düzenli bir geometriye sahip olduğu, KDD ile modellenen doğrusal problemler için mevcuttur. Bu gibi durumlarda, malzemenin benzer bir basit geometrisi üzerinde deney yapılırsa, deneyde ölçülen büyüklükler aynı geometrideki analitik çözüme uydurularak malzeme özellikleri belirlenebilir. Örneğin, silindirik bir numuneye uygulanan basit tek yönlü çekme testinde, $\sigma$ gerilmesi ve $\varepsilon$ gerinimi ölçülebileceğinden, silindiri oluşturan malzemenin $E$ Young modülü, $\sigma=E \varepsilon$ formülüyle rahatlıkla bulunabilir. Ancak, geometrinin ve/veya yüklemenin daha karmaşı olduğu bir deneysel konfigürasyonun, analitik çözümü genelde yoktur ve bu konfigürasyon üzerinde analitik yollarla malzeme özelliği belirlemek mümkün olmaz. SEY yönteminin avantajı ise, herhangi bir geometri üzerinde analitik çözüm hassasiyetinde sonuç üretebilmesidir. Dolayısıyla, analitik çözümün olmadığı durumlarda deney sonuçlarını, aynı konfigürasyon üstünde elde edilen SEY sonuçlarına uydurarak da malzeme özelliği belirlemek mümkündür.

Eklem kıkırdağı, menisküs, tendon gibi yumuşak bağ dokularının malzeme özellikleri dokuların in vivo işlevlerini yerine getirebilmelerinde ciddi rol oynar [1]. Bu dokuların ortak özelliği iki fazlı olmaları ve zamana bağlı deformasyon davranışına sahip olmalarıdır. Özellikle, kıkırdak dokusunun malzeme özellikleri, doku artrit gibi çok yaygın bir rahatsızlığa maruz kaldığı ve bu rahatsızlığın etyolojisi malzeme özellikleri ile ilgili olduğu için [2], aynı zamanda doku mühendisliği ile üretildiği için [3], önem arz etmektedir.

Kıkırdağın ve kıkırdağımsı dokuların malzeme özelliklerini deneysel olarak belirlemeye yönelik çalışmalar literatürde geniş bir yer tutar ve başka kaynaklarda özetlenmiştir [4]. Çok basit deneysel geometrilerde, doku denge durumuna geldiğinde kıkırdak katı fazının Young modülü ve/veya Poisson oranı hesaplanabilir. Dokunun hidrolik geçirgenliğini belirlemek ise deneysel olarak daha zorlu bir süreçtir. Aynı anda hem Young modülü (ve/veya Poisson oranı) ve geçirgenliği belirlemek ise en genel şekliyle ancak bu çalışmada tarif edeceğimiz gibi SEY optimizasyonu ile mümkündür.

$\mathrm{Bu}$ makalede, iki fazlı dokuların, özelde eklem kıkırdağının malzeme özelliklerini SEY kullanarak belirlemenin matematiksel formülasyonunu sunup örneklendireceğiz.

\section{SONLU ELEMANLAR OPTIMIZASYONU}

Optimizasyonda, tipik olarak amaç fonksiyonu olarak anılan bir fonksiyonun ekstremum noktasını bulmak hedeflenir. Malzeme özellikleri kestiriminde, amaç fonksiyonu genellikle deneysel çıktıları içeren $m$ vektörü ile aynı niceliklerin deneyin SEY simülasyonundaki değerlerini içeren y vektörü arasındaki hatayı ifade eder. SEY çıktılarının değeri, yani y vektörünün değeri, malzeme özelliklerine bağlıdır. İlgili malzeme özelliklerinin değerlerini bir $\theta$ vektörüne yazarsak, bu durum Eşitlik 1'deki gibi ifade edilebilir.

$\mathbf{y}=\mathbf{y}(\boldsymbol{\theta})$

Amaç fonksiyonu, malzeme özelliklerine doğrudan ve/veya SEY sonuçları üstünden bağlı olabilir. Buna göre, amaç fonksiyonu f Eşitlik 2'de 
$\mathrm{f}=\mathrm{f}(\mathbf{m}, \mathbf{y}(\boldsymbol{\theta}), \boldsymbol{\theta})$

görüldüğü gibi tarif edilir. İncelenen matematiksel problemin doğrusallığından bağımsız olarak, $\mathbf{y}(\boldsymbol{\theta})$ teriminde $\mathbf{y}$ ve $\boldsymbol{\theta}$ arasındaki fonksiyonel ilişki genelde doğrusal değildir. $\mathrm{Bu}$ yüzden $\mathrm{f}$ ile $\theta$ arasındaki ilişki de doğrusal değildir. Doğrusal olmayan denklemlerin kökü genelde iterasyon yöntemleriyle buluruz.

Optimizasyon problemlerini çözmek için kullanılan yöntemler gradyan ("gradient) ve gradyan olmayan ("nongradient") yöntemler olarak sınıflandırılabilir. Gradyan yöntemlerde, malzeme özelliklerinin o anki tahmini değerlerine art arda küçük farklar eklenerek hatanın yavaş yavaş azalması sağlanır. $\mathrm{Bu}$ yöntemin uygulanabilmesi için, $\mathrm{f}$ fonksiyonunun bilinmeyenlere göre bir gradyanının hesaplanabilmesi gerekir. Newton-Raphson ve en hizlı azalma ("steepest descent") yöntemi en sık kullanılan gradyan yöntemlerdendir. Birçok optimizasyon probleminde, amaç fonksiyonu sürekli değildir ve bir gradyan hesaplanması mümkün olmaz. Genetik algoritmalar, gradyan olmayan yaklaşımlara verilebilecek en klasik örnektir. SEY kullanarak çözdüğümüz problemler genellikle sürekli problemlerdir ve malzeme özellikleri de sürekli niceliklerdir. Bu nedenle, amaç fonksiyonunun gradyanı genellikle mevcuttur ve gradyan optimizasyonu ile ekstremumu bulunabilir.

\section{3. İKI FAZLI DOKULARDA SONLU ELEMANLAR OPTIMIZASYONU}

\section{1. İki Fazlı Teori}

Kıkırdak dokusu eklem sıvısıyla doymuş (yani satüre olmuş) gözenekli bir yapıdır. Üzerine yük bindiğinde eklem sıvısı basınç altında katı matris içinde yavaş yavaş hareket eder, bu yüzden kıkırdak gibi iki fazlı bir dokunun deformasyonu elastik malzemelerin aksine zamana bağlıdır. Eklem sıvısı, basıncıyla yükün çoğunu taşıyarak katı matrise az yük düşmesini sağlar. Bu mekanizma sayesinde doku, işlevini dejenere olmadan uzun yıllar yerine getirebilir. İki fazlı teori, orijinal olarak Mow ve arkadaşları [5] tarafından eklem kıkırdağı için bu yük taşıma mekanizmasını açıklayacak şekilde geliştirilmiş, ancak daha sonra cilt [6], beyin [7], omurga diskleri [8], atardamarlar [9] da dahil olmak üzere vücuttaki farklı yumuşak dokuları modellemek için kullanılmışıır. Bu teoride, biri katı ve biri sıvı olmak üzere iki sürekli ortamın aynı anda aynı uzayı kapladığı ("superposition") kabul edilir. Kıkırdağın zamana bağlı deformasyon davranışı, iki fazlı teori tarafından iyi bir şekilde açıklanmaktadır.

\subsection{Doğrusal İki Fazlı Sonlu Elemanlar}

Mühendislikte, aynı problem için birden fazla SEY formülasyonu mümkündür. İki fazlı yumuşak dokuları modellemek için de birkaç farklı formülasyon başarılı bir şekilde türetilmiş ve uygulanmıştır. İnşaat mühendisliğinde ötelenmebasınç formülasyonu (ya da kısaca upformülasyonu) olarak anılan ve toprak konsolidasyonu probleminden kaynaklanan bir formülasyon, sayısal verimliliği nedeniyle tercih edilir olmuştur. $\mathrm{Bu}$ formülasyonda, bağımsız değişkenler $\mathbf{u}$ katı faz ötelenmesi ve $\mathrm{p}$ basıncıdır. $\mathbf{v}$ katı faz hızının bilinmeyen olarak u'nun yerini aldığı hız-basınç formülasyonu (ya da kısaca vpformülasyonu) olarak adlandırılan ve upformülasyonu ile yakından ilişkili olan bir formülasyon da mevcuttur [10].

vp-formülasyonu için, öncelikle sıvı fazın hızı, iki fazlı teori denklemlerinden cebirsel manipülasyonla yok edilir. Sıvı fazın kati matris içindeki hızı çok düşük olduğu için viskoz etkiler göz ardı edilir. Buna paralel olarak, katı faz ile sıvı faz arasındaki momentum transferinin hidrolik geçirgenlik ile ilgili olduğu ve sıvı fazın sadece hidrostatik bir gerilme (yani p basıncı) taşıyabileceği varsayılır. $\mathrm{Bu}$ kabullerle iki fazlı teorinin denklemleri Eşitlik 3 ve 4'te verilmiştir:

$\nabla \cdot(\mathbf{v}-\kappa \nabla p)=0$

$\nabla \cdot\left(\boldsymbol{\sigma}^{\mathrm{E}}-\mathrm{p} \mathbf{I}\right)=0$

Burada Eşitlik 3 katı faz ve sıvı fazın etkileşimini, Eşitlik 4 ise her dokunun her noktasındaki kuvvet 
dengesini ifade etmektedir. Eşitliklerde $\kappa$ dokunun hidrolik geçirgenliğini, $\sigma^{\mathrm{E}}$ ise katı faz üstündeki elastik gerilmeyi ifade etmektedir. (I birim matristir.) Problem geometrisinin sinırının bir kısmında katı faz belli bir $\overline{\mathbf{v}}$ hızıyla hareket ediyor ya da dokuya belli bir $\overline{\mathrm{p}}$ basınç uygulanıyor olabilir. Bu sınır koşulları, ilgili sınırlarda Eşitlik 5 ve 6' daki

$\mathbf{v}=\overline{\mathbf{v}}$

$\mathrm{p}=\overline{\mathrm{p}}$

gibi ifade edilir. Dokunun üstüne, dağılmış bir $\overline{\mathbf{t}}$ yükü bindiğinde bu yük dokuda hem katı hem sıv1 faz tarafında taşınır. Bu sınır koşulu ise Eşitlik 7

$$
\left(\boldsymbol{\sigma}^{\mathrm{E}}+\mathrm{pI}\right) \cdot \mathbf{n}=\overline{\mathbf{t}}
$$

şeklinde ifade edilir. Burada n sınırdaki yüzey normalini ifade eden birim vektördür. Matematiksel olarak, sınırın bir kısmında $\overline{\mathrm{Q}}$ sıvı akısına da bir değer vermek mümkündür ve bu Eşitlik 8 ile ifade edilir. $\mathrm{Bu}$ sınır koşulunun genelde fizyolojik bir karşılığ1 yoktur.

$$
\overline{\mathrm{Q}}=-\kappa \nabla \mathrm{p} \cdot \mathbf{n}
$$

vp-formülasyonunun ayrıntıları literatürde verilmiştir $[11,12]$ ve biz bu çalışmada sadece özetlemekle yetineceğiz. $3,4,7$ ve 8 numaralı eşitlikler uygun ağırlık fonksiyonları ile çarpılıp problem geometrisi üstünde integralleri alınır ve Gauss Teoremi yardımıla türev dereceleri düşürülürse, ilgili SEY probleminin zayıf formu ("weak form") elde edilir. v, u ve p büyüklüklerinin düğümsel şekil fonksiyonları aracılığıyla interpolasyonu gerçekleştirilir. Katı fazın lineer elastik kabul edildiği doğrusal analizde, bu adımlardan sonra ortaya çıkan matris denklemi Eşitlik 9'daki gibi ifade edilebilir:

$$
\left[\begin{array}{cc}
\mathbf{0} & -\mathbf{A} \\
-\mathbf{A}^{\mathrm{T}} & -\mathbf{H}(\boldsymbol{\theta})
\end{array}\right]\left[\begin{array}{c}
\mathbf{v}^{\mathrm{n}} \\
\mathbf{p}^{\mathrm{n}}
\end{array}\right]+\left[\begin{array}{cc}
\mathbf{K}(\boldsymbol{\theta}) & \mathbf{0} \\
\mathbf{0} & \mathbf{0}
\end{array}\right]\left[\begin{array}{c}
\mathbf{u}^{\mathrm{n}} \\
\mathbf{0}
\end{array}\right]=\left[\begin{array}{c}
\mathbf{F}_{\mathrm{t}} \\
\mathbf{F}_{\mathrm{Q}}
\end{array}\right]
$$

Burada, $\mathbf{v}^{\mathrm{n}}, \mathbf{u}^{\mathrm{n}}$ ve $\mathbf{p}^{\mathrm{n}}$, hız, yer değiştirme ve basınç değişkenlerinin düğüm değerlerini gösterir. A matrisi sıvı ve katı fazların etkileşimini ifade eder, $H$ ise sıvı fazın sıkılık matrisidir. Sirasıyla $\mathbf{K}$ ve $\mathbf{F}_{\mathrm{t}}$, SEY ile lineer elastik gerilme analizinde karşımıza çıkan standart sıkılık matrisi ve kuvvet vektörüdür. Eşitlik 9, t=0 anı için bulunan çözümün sonlu farklar yaklaşımıyla zaman içinde ilerletildiği birinci derecede bir diferansiyel cebirsel sistemdir. Dolayısıyla, $\mathbf{v}$ hızı ve u ötelenmesi CrankNicholson formülüyle Eşitlik 10'daki gibi ilintilendirilebilir.

$\mathbf{u}_{\mathrm{k}+1}^{\mathrm{n}}=\left(\omega \mathbf{v}_{\mathrm{k}+1}^{\mathrm{n}}+(1-\omega) \mathbf{v}_{\mathrm{k}}^{\mathrm{n}}\right) \Delta \mathrm{t}+\mathbf{u}_{\mathrm{k}}^{\mathrm{n}}$

Burada altsimge, zaman adımına atıfta bulunmaktadır. $\Delta$ t zaman adımının büyüklüğü ve $\omega$ zaman integrali parametresidir. Eşitlik 10, Eşitlik 9'da ya u ya da v'yi yok etmek için kullanılabilir. vp-formülasyonu'nda u niceliği yok edilir ve Eşitlik 11 formunu alır.

$$
\left[\begin{array}{cc}
\omega \Delta t \mathbf{K}(\boldsymbol{\theta}) & -\mathbf{A} \\
-\mathbf{A}^{\mathrm{T}} & -\mathbf{H}(\boldsymbol{\theta})
\end{array}\right]\left[\begin{array}{l}
\mathbf{v}_{\mathrm{k}+1}^{\mathrm{n}} \\
\mathbf{p}_{\mathrm{k}+1}^{\mathrm{n}}
\end{array}\right]=\left[\begin{array}{c}
\mathbf{F}_{\mathrm{t}}-\mathbf{K}(\boldsymbol{\theta})\left(\mathbf{u}_{\mathrm{k}}^{\mathrm{n}}+\mathbf{v}_{\mathrm{k}}^{\mathrm{n}}(1-\omega) \Delta \mathrm{t}\right) \\
\mathbf{F}_{\mathrm{Q}}
\end{array}\right]
$$

Görüldüğü gibi, k. zaman adımında elde edilen çözüm, eşitliğin sağ tarafının güncellenmesi için kullanılır ve sistemin $(\mathrm{k}+1)$. zaman adımındaki çözümü bulunur. $\Delta \mathrm{t}$ ve $\omega$ nicelikleri analiz boyunca değişmedikçe denklem sisteminin sol tarafı (yani katsayı matrisi) hiç değişmez; sistem, aynı katsayı matrisi ve her zaman anına değişen sağ taraf vektörü ile tekrar tekrar çözülerek problemin zamana bağlı olan çözümü elde edilir.

Eşitlikte görülen $\mathbf{K}$ alt matrisi, elastik katı fazın E Young Modülü ve $v$ Poisson Oranı'nın, H alt matrisi ise dokunun $\kappa$ geçirgenliğinin birer fonksiyonudur. Dolayısıyla, SEY geometrisi ve kafesi aynı kalsa dahi, malzeme özellikleri değiştiğinde bu alt matrislerde de değişiklik olacaktır. Belirlenecek malzeme özelliklerini $\theta$ vektöründe toplarsak, $\mathbf{K}$ ve $\mathbf{H}$ bu vektörün birer fonksiyonudur.

\section{3. İki Fazlı Optimizasyon Analiz İçin Amaç Fonksiyonları}

Daha önce belirtildiği gibi, amaç fonksiyonu deneysel ve SEY çıktısı arasındaki hatanın bir 
ölçüsüdür. Bir deneyde, belli nicelikleri ancak belli noktalarda gözlemleyebiliriz. En basit amaç fonksiyonu, gözlem noktalarındaki bu hataların karelerinin ağırlıklı bir toplamı olarak basitçe Eşitlik 12'deki gibi ifade edilebilir:

$$
\mathbf{J}=(\mathbf{m}-\mathbf{y}(\boldsymbol{\theta}))^{\mathrm{T}} \mathbf{Q}(\mathbf{m}-\mathbf{y}(\boldsymbol{\theta}))
$$

Burada Q köşegen formlu bir ağırlık matrisidir. Deney sırasında gözlem noktalarında farklı doğada büyüklükler (örneğin hız ve basınç) ölçülüyorsa, bunlardaki hatalar birbiriyle doğrudan toplanamaz. Q matrisi farklı türde hataların doğru katsayılarla çarpılarak boyutsuz hale getirilmesini sağlar. İki fazlı dokular, zamana bağlı deformasyon davranışına sahiptir, dolayısıyla aynı düğümde farklı zamanlarda yapılan gözlemler $\mathbf{m}$ ve $\mathbf{y}$ vektörlerinde farklı girdiler olarak yer alır.

\subsection{Amaç Fonksiyonunun Minimize Edilmesi}

Sonuçların, malzeme özelliklerinin sürekli birer fonksiyonu olduğu düşünülürse, amaç fonksiyonunu gradyan bir yöntem ile minimize etmek en mantıklı olan yaklaşımdır.

Gradyan yöntemde, $\theta$ malzeme özelliği vektöründe $\delta \theta$ kadar sonsuz küçüklükte bir varyasyonunun, amaç fonksiyonunda nasıl bir varyasyon yaratacağına bakarız. Deney ve simülasyon arasındaki hatayı sıfırlayan optimal (gerçek) malzeme özellikleri için amaç fonksiyonu minimize olmuş olacağından, bu varyasyonun sıfır olması gerekir (Eşitlik 13).

$$
\delta \mathrm{J}=-(\delta \mathbf{y})^{\mathrm{T}} \mathbf{Q}(\mathbf{m}-\mathbf{y})-(\mathbf{m}-\mathbf{y})^{\mathrm{T}} \mathbf{Q}(\delta \mathbf{y})=0
$$

Q, köşegen matris olduğu için yukardaki denklem şöyle basitleştirilebilir (Eşitlik 14):

$$
\delta \mathrm{J}=-(\delta \mathbf{y})^{\mathrm{T}} \mathbf{Q}(\mathbf{m}-\mathbf{y})=0
$$

y vektöründeki $\delta \mathbf{y}$ varyasyonu, (Eşitlik 15)

$$
\delta \mathbf{y}=\frac{\partial \mathbf{y}}{\partial \boldsymbol{\theta}} \delta \boldsymbol{\theta}=\mathbf{S} \delta \boldsymbol{\theta}
$$

$\delta \theta$ cinsinden olarak yazılabilir. Gözlem noktalarındaki SEY sonuçlarının, yani y'nin, malzeme özelliklerindeki değişime hassasiyetini ifade eden $\mathbf{S}$ matrisine hassasiyet matrisi ("sensitivity matrix") adını veriyoruz. Bu matrisin hesaplanması SEY optimizasyonundaki en kritik adımdır. Eşitlik 14, S kullanılarak Eşitlik 16'daki gibi yazılabilir.

$$
\delta \mathrm{J}=-(\delta \boldsymbol{\theta})^{\mathrm{T}}\left[\mathbf{S}^{\mathrm{T}} \mathbf{Q}(\mathbf{m}-\mathbf{y})\right]=0
$$

$\delta \theta$ niceliği gelişigüzel seçilebileceğine göre, Eşitlik 14'ün sağlanması için ayraç içindeki terimin sıfırlanması gerekir. Yani;

$$
\mathbf{r}(\boldsymbol{\theta})=\mathbf{S}^{\mathrm{T}} \mathbf{Q}(\mathbf{m}-\mathbf{y})=0
$$

Burada $\mathbf{r}(\boldsymbol{\theta})$ simgesi ile gösterilen denklem sistemi, $\theta$ bilinmeyeni cinsinden doğrusal olmayan bir sistemdir ve iterasyon içeren bir yöntemle ile çözülmelidir. Yaygın olarak kullanılan NewtonRaphson yöntemi için Eşitlik $17 \boldsymbol{\theta}=\boldsymbol{\theta}^{1}$ gibi tahmini bir malzeme özelliği grubu değeri etrafında doğrusallaştırılırsa: (Eşitlik 18)

$\left.\frac{\partial \mathbf{r}(\boldsymbol{\theta})}{\partial \boldsymbol{\theta}}\right|_{\boldsymbol{\theta}=\boldsymbol{\theta}^{1}} \delta \boldsymbol{\theta}^{1+1}=-\mathbf{r}\left(\boldsymbol{\theta}^{l}\right)$

şeklinde lineer bir denklem sistemi ortaya çıkar. Burada $\theta^{1}$ bir önceki iterasyondan elde edilen tahmini malzeme özelliklerini, $\delta \theta^{1+1}$ ise sistem çözüldüğünde elde edilecek ve $\theta^{1}$ değerini güncellemek için kullanılacak düzeltme terimini ifade etmektedir.

Eşitlik 17'de verilen $\mathbf{r}(\boldsymbol{\theta})$ teriminin $\theta$ 'ya göre türevi alınırsa Eşitlik 19 elde edilir.

$\left.\frac{\partial \mathbf{r}(\boldsymbol{\theta})}{\partial \boldsymbol{\theta}}=-\left(\mathbf{S}^{1}\right)^{\mathrm{T}} \mathbf{Q} \mathbf{S}^{1}\right)+\left(\mathbf{m}-\mathbf{y}^{1}\right)^{\mathrm{T}} \mathbf{Q} \frac{\partial \mathbf{S}^{1}}{\partial \boldsymbol{\theta}}$

S hassasiyet matrisinin $\theta$ 'ya göre türevi ikinci derece bir terimidir ve hesaplanması zahmetlidir. Dolayısıyla, bu tür çözüm yaklaşımlarında bu terim genellikle göz ardı edilir. Bu varsayımla Eşitlik 20 formunda yazılabilir. 


$$
\left[\left(\mathbf{S}^{1}\right)^{\mathrm{T}} \mathbf{Q} \mathbf{S}^{1}\right]\left(\delta \boldsymbol{\theta}^{1+1}\right)=\left(\mathbf{S}^{1}\right)^{\mathrm{T}} \mathbf{Q}\left(\mathbf{m}-\mathbf{y}^{1}\right)
$$

Sistem, $\delta \theta^{1+1}$ için çözüldüğünde, malzeme özellikleri için mevcut tahmin Eşitlik 21'deki şekilde güncellenir:

$$
\boldsymbol{\theta}^{1+1}=\boldsymbol{\theta}^{1}+\delta \boldsymbol{\theta}^{1+1}
$$

ve prosedür tekrarlanır. Dikkat edilecek olursa, yakınsak bir süreçte malzeme özellikleri doğru değerlere yaklaşırken Eşitlik 20'nin sağ tarafında m ve $\mathbf{y}$ terimleri de birbirine yaklaşacak ve $\delta \theta^{1+1}$ terimi norm olarak gittikçe küçülecektir.

\subsection{Hassasiyet Matrisinin Hesaplanması}

Hassasiyet matrisinin belirlenmesi optimizasyondaki en önemli adımdır.

Malzeme özelliklerindeki bir $\delta \boldsymbol{\theta}$ değişimi, Eşitlik 9'daki $\mathbf{K}$ ve $\mathbf{H}$ matrislerini değiştirerek $\mathbf{u}, \mathbf{v}$ ve $\mathrm{p}$ çözümlerinin de farklılaşmasına yol açar. Eşitlik 9'un malzeme özelliklerine göre bir varyasyonunu alalım (Eşitlik 22).

$$
\begin{aligned}
-\mathbf{A} \delta \mathbf{p}^{\mathrm{n}}+\mathbf{K} \delta \mathbf{u}^{\mathrm{n}}+\delta \mathbf{K} \mathbf{u}^{\mathrm{n}}=\mathbf{0} \\
-\mathbf{A}^{\mathrm{T}} \delta \mathbf{v}^{\mathrm{n}}-\mathrm{H} \delta \mathbf{p}^{\mathrm{n}}-\delta \mathbf{H} \mathbf{p}^{\mathrm{n}}=\mathbf{0}
\end{aligned}
$$

Sırasıyla v, u ve p'ye karşılık gelen $\mathbf{V}, \mathbf{U}$ ve $\mathbf{P}$ hassasiyet matrisleri, sonlu elemanlar kafesinin her düğümünde, ilgili büyüklüğün her bileşeni için hassasiyet değerini içeren matrislerdir. Bunlar matematiksel olarak (Eşitlik 23).

$$
\delta \mathbf{v}^{\mathrm{n}}=\mathbf{V}^{\mathrm{n}} \delta \boldsymbol{\theta} \quad \delta \mathbf{u}^{\mathrm{n}}=\mathbf{U}^{\mathrm{n}} \delta \boldsymbol{\theta} \quad \delta \mathbf{p}^{\mathrm{n}}=\mathbf{P}^{\mathrm{n}} \delta \boldsymbol{\theta}
$$

şeklinde tanımlanabilirler. $\mathbf{K}$ ve $\mathbf{H}$ matrislerindeki varyasyonlar ise Eşitlik 24 olarak ifade edilebilir.

$$
\delta \mathbf{K}=\frac{\partial \mathbf{K}}{\partial \boldsymbol{\theta}} \delta \boldsymbol{\theta} \quad \delta \mathbf{H}=\frac{\partial \mathbf{H}}{\partial \boldsymbol{\theta}} \delta \boldsymbol{\theta}
$$

Yukardaki terimler Eşitlik 22'de yerlerine yazılırsa, denklem Eşitlik 25'de verilen şekle dönüşür.

$$
\begin{aligned}
& {\left[\mathbf{A} \mathbf{P}^{\mathrm{n}}+\mathbf{K} \mathbf{U}^{n}+\frac{\partial \mathbf{K}}{\partial \boldsymbol{\theta}} \mathbf{u}^{\mathrm{n}}\right] \delta \boldsymbol{\theta}=\mathbf{0}} \\
& {\left[-\mathbf{A}^{\mathrm{T}} \mathbf{V}^{\mathrm{n}}-\mathbf{H} \mathbf{P}^{\mathrm{n}}-\frac{\partial \mathbf{H}}{\partial \boldsymbol{\theta}} \mathbf{p}^{\mathrm{n}}\right] \delta \boldsymbol{\theta}=\mathbf{0}}
\end{aligned}
$$

$\delta \theta$ gelişigüzel bir nicelik olduğuna göre, yukardaki denklemlerin sağlanması ayraç içinde kalan terimlerin sıfırlanması ile mümkündür ki bu aşağıdaki sistemin çözülmesi ile sağlanabilir (Eşitlik 26).

$$
\left[\begin{array}{cc}
\mathbf{0} & -\mathbf{A} \\
-\mathbf{A}^{\mathrm{T}} & -\mathbf{H}
\end{array}\right]\left[\begin{array}{c}
\mathbf{V}^{\mathrm{n}} \\
\mathbf{P}^{\mathrm{n}}
\end{array}\right]+\left[\begin{array}{cc}
\mathbf{K} & \mathbf{0} \\
\mathbf{0} & \mathbf{0}
\end{array}\right]\left[\begin{array}{c}
\mathbf{U}^{\mathrm{n}} \\
\mathbf{0}
\end{array}\right]=\left[\begin{array}{c}
-\frac{\partial \mathbf{K}}{\partial \boldsymbol{\theta}} \mathbf{u}^{\mathrm{n}} \\
\frac{\partial \mathbf{H}}{\partial \boldsymbol{\theta}} \mathbf{p}^{\mathrm{n}}
\end{array}\right]
$$

Denklem sisteminin sağ tarafinın $\mathbf{u}$ ve $\mathrm{p}$ ile birlikte zamana bağlı olarak değiştiğine bakarak, hassasiyet matrislerinin zamana bağlılığı gözlemlenebilir. v hızı ve u ötelenmesi arasındaki ilintiyi tanımlayan ve Eşitlik 10 ile verilen ifade, $\mathbf{V}$ ve $\mathbf{U}$ hassasiyet matrisleri arasında da geçerlidir. Yani, hassasiyetlerin $\mathrm{k}$. ve $\mathrm{k}+1$. zaman adımlarındaki değerleri arasındaki ilişki Eşitlik 27 denklemiyle tanımlidir.

$\mathbf{U}_{\mathrm{k}+1}^{\mathrm{n}}=\left(\omega \mathbf{V}_{\mathrm{k}+1}^{\mathrm{n}}+(1-\omega) \mathbf{V}_{\mathrm{k}}^{\mathrm{n}}\right) \Delta \mathrm{t}+\mathbf{U}_{\mathrm{k}}^{\mathrm{n}}$

Eşitlik 27, Eşitlik 26'ya konulup düzenleme yapılırsa, Eşitlik 28 sistemi elde edilir.

$$
\left[\begin{array}{cc}
\omega \Delta \Delta \mathbf{K}(\boldsymbol{\theta}) & -\mathbf{A} \\
-\mathbf{A}^{T} & -\mathbf{H}(\boldsymbol{\theta})
\end{array}\right]\left[\begin{array}{l}
\mathbf{V}_{k+1}^{n} \\
\mathbf{P}_{k+1}^{n}
\end{array}\right]=\left[\begin{array}{c}
-\frac{\partial \mathbf{K}}{\partial \boldsymbol{\theta}} \mathbf{u}_{k+1}^{n}-\mathbf{K}(\boldsymbol{\theta})\left(\mathbf{V}_{k}^{n}+\mathbf{V}_{k}^{n}(1-\omega) \Delta t\right) \\
\frac{\partial \mathbf{H}}{\partial \boldsymbol{\theta}} \mathbf{p}_{k+1}^{n}
\end{array}\right]
$$

Eşitlik 28'de verilen sistem, SEY simülasyonunda çözülen ve Eşitlik 11 'de verilen sistemle aynı katsayı matrisine sahiptir. Her iki sistemin sadece sağ tarafları birbirinden farklıdır. Dolayısıyla, SEY simülasyonu yapılırken aynı anda hassasiyet analizi de ciddi bir ekstra hesaplama yükü altına girmeden yapılabilir. Deneysel büyüklükler deneyin hangi zaman anlarında ve hangi gözlem noktalarında okunmuşsa, deneyin SEY simülasyonunda da aynı büyüklükler, aynı gözlem noktalarına denk düşen düğümlerde ve aynı zaman anlarında hesaplanır. 
Eşzamanlı olarak bu büyüklüklerin hassasiyet değerleri de bulunur. Hesaplanan hassasiyet değerleri ile $\mathbf{S}$ matrisi oluşturulur, Eşitlik 20'deki sistem kurulur ve çözülür. Çözüm sonucunda elde edilen $\delta \theta$ vektörü ile malzeme özellikleri Eşitlik 21'e göre güncellenir ve SEY simülasyonu güncellenmiş malzeme özellikleri ile yeniden çalıştırılır. $\mathrm{Bu}$ işlem malzeme özellikleri yakınsayıncaya dek tekrar edilir. Tarif edilen prosedürün akış diyagramı Şekil 1'de verilmiştir.

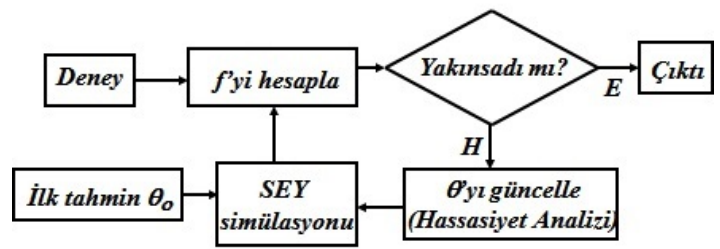

Şekil 1. Sonlu elemanlar optimizasyonunun prosedürünün akış diyagramı

\section{4. ÖRNEKLER}

Yukarda açıklanan prosedüre göre, iki fazlı doku problemi ve ilgili optimizasyon şeması, C++ dilinde, rutin SEY işlemleri için kütüphanelerin mevcut olduğu bir hesaplama ortamında programlanmıştır.

Belirli malzeme özellikleri ile SEY simülasyonu yapmak matematiksel olarak bir "ileri problem" iken belli bir çıktıyı verecek malzeme özelliklerini belirlemek bir "ters problemdir". Ters problem algoritmalarını test etmenin en sık başvurulan yolu, ileri problem aracılığıyla "sanal" deneysel veri üretmek ve ters problem algoritmasının bu verileri üreten parametreleri (bu örnekte malzeme özelliklerini) doğru tahmin edip etmediğini sinamaktır.

Örnek problemler olarak, kıkırdağa sıklıkla uygulanan iki deneysel konfigürasyon seçilmiştir. Yanal kısıtlı sıkıştırma ("confined compression”) dokunu kapalı bir silindir içine konulup sıvı geçiren bir piston ile sıkıştırılmasını içerir (Şekil 2). Kıkırdak dokusu sadece sıkıştırma yönünde deforme olacağından dolayı bu konfigürasyon özünde tek yönlü bir probleme tekabül eder. Yanal kısıtsız sıkıştırma ("unconfined compression") deneyinde ise doku numunesi iki plaka arasında sıkıştırılır (Şekil 2). Bu konfigürasyon eksenel simetriye sahiptir ve SEY simülasyonunda üç boyutlu bir probleme tekabül eder.

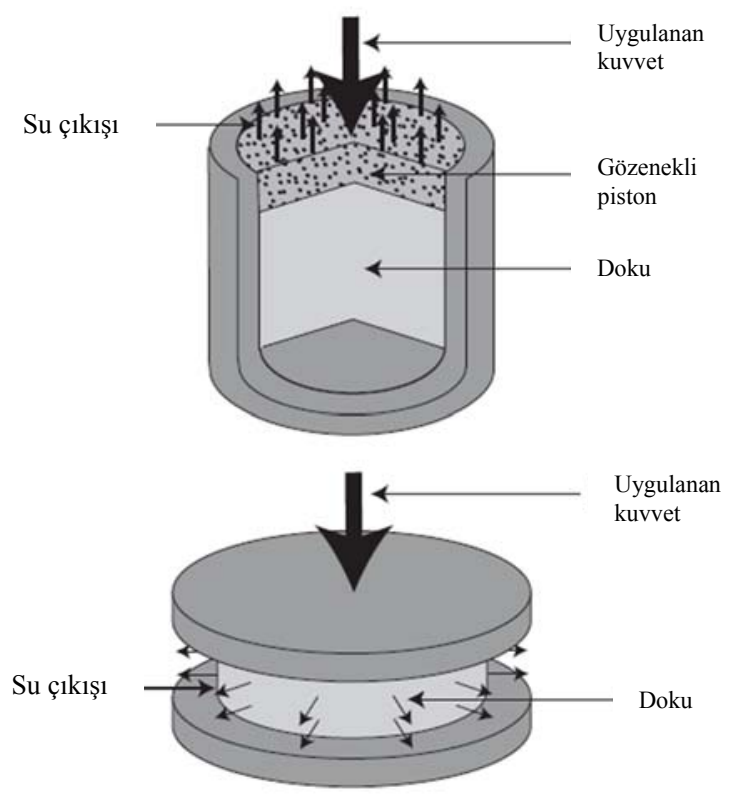

Şekil 2. Kıkırdak dokusu üstünde sıklıklı uygulanan yanal kısıtlı (üst) ve yanal kısıtsız (alt) sıkıştırma testleri [1]

Yanal kısıtlı sıkıştırma problemi için bir kafes oluşturulmuş (Şekil 3) ve bu geometri üstünde SEY ile bir sanal deney uygulanmıştır.

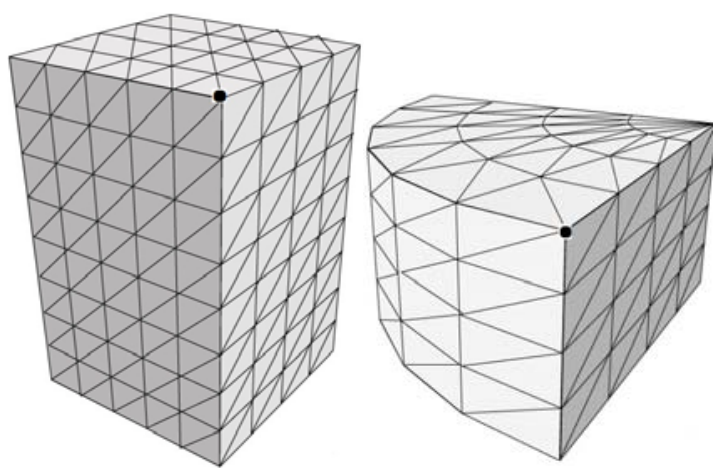

Şekil 3. Yanal kısıtlı (sol) ve yanal kısıtsız (sağ) sıkıştırma geometrileri ve SEY kafesleri. Deney gözlem noktaları siyah nokta ile gösterilmiştir 
Bu deneyde malzeme özellikleri olarak $\mathrm{E}=0,5 \mathrm{MPa}$ ve $\kappa=0,0025 \mathrm{~mm}^{4} / \mathrm{Ns}$ değerleri alınmış, gözlem noktası olarak pistonun altındaki bir nokta seçilmiştir. Bu noktadaki eksenel ötelenmenin $\mathrm{t}=10$, 30, 100 s. zaman noktalarındaki değerleri deneysel veriler olarak kaydedilmiştir. Sanal deneyden elde edilen veriler, gerçek bir deneyden elde edilmiş gibi optimizasyon programına verilmiştir. Malzeme özelliklerinin başlangıç değerleri, sanal deneysel verilerin elde edilmesinde kullanılan değerlerinden çok farklı olarak $\left(E=2,5 \mathrm{MPa}\right.$ ve $\left.\kappa=0,01 \mathrm{~mm}^{4} / \mathrm{Ns}\right)$ verilmiştir. Buna karşın hem E Young modülü (Şekil 4), hem de $\kappa$ doku geçirgenliği (Şekil 5) için malzeme özellikleri yaklaşık on iterasyonda gerçek değerlerine yakınsamaktadır.

Yanal kısıtsız sıkıştırma testinde (Şekil 3), gözlem noktası olarak üst plakanın altında ve doku numunesinin dıș kenarında yer alan bir nokta belirlenmiştir. $\mathrm{Bu}$ noktanın $\mathrm{t}=10$, 30, 100, $400 \mathrm{~s}$. zaman anlarındaki radyal ötelenmesi deneysel veri olarak kabul edilmiştir. Gerçek değerlerinden çok farklı başlangıç değerleri verilen malzeme özellikleri değerleri $(\mathrm{E}=2,5 \mathrm{MPa}$ ve $\kappa=0,007 \mathrm{~mm}^{4} / \mathrm{Ns}$ ) yine yaklaşı $\mathrm{k}$ on iterasyonda doğru değerlere yakınsamaktadır.

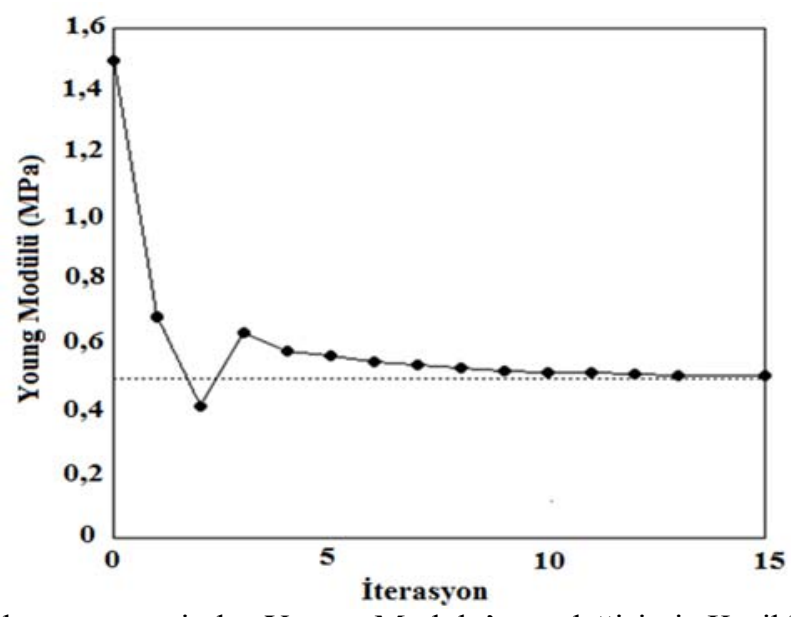

Şekil 4. Yanal kısıtlı sıkıştırma testinde, Young Modülü’nün değişimi. Kesikli çizgi bu parametrenin gerçek değerini ifade etmektedir

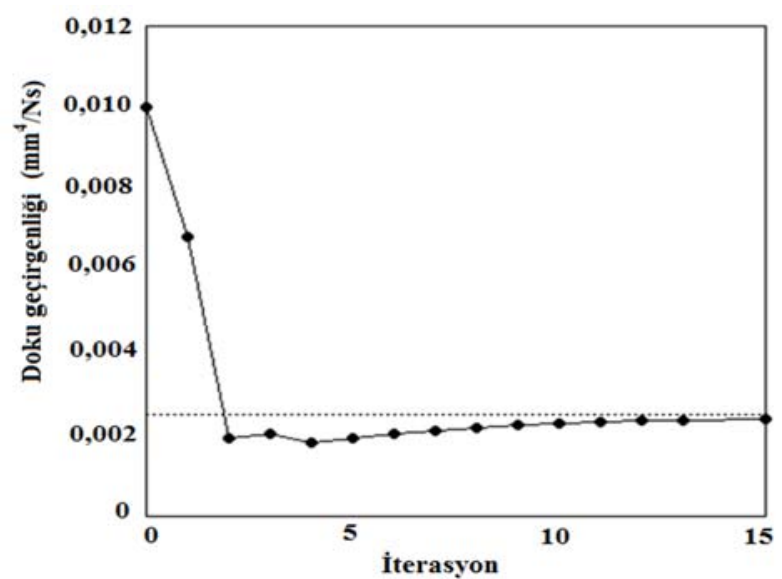

Şekil 5. Yanal kısıtlı sıkıştırma testinde, doku geçirgenliğinin değişimi. Kesikli çizgi bu parametrenin gerçek değerini ifade etmektedir 


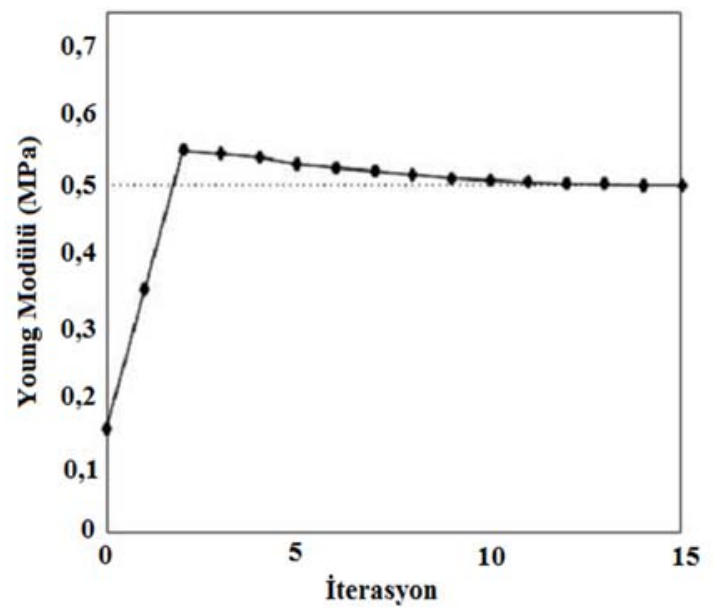

Şekil 6. Yanal kısıtsız sıkıştırma testinde, Young Modülü'nün değişimi. Kesikli çizgi bu parametrenin gerçek değerini ifade etmektedir

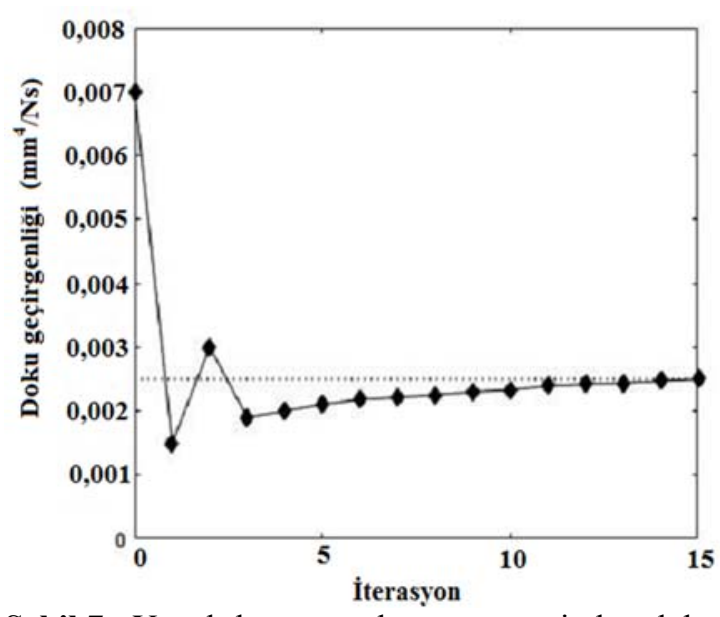

Şekil 7. Yanal kısıtsız sıkıştırma testinde, doku geçirgenliğinin değişimi. Kesikli çizgi bu parametrenin gerçek değerini ifade etmektedir

\section{TARTIŞMA VE SONUÇ}

Bu çalışmada, SEY ve hassasiyet analizi ile iki fazlı yumuşak doku malzeme özelliklerinin analitik olarak nasıl belirlenebileceğini sunduk. Aslen bir optimizasyon problemi olan bu problemin çözümünün sunulan yaklaşımla efektif olarak gerçekleştirilebildiği ortaya konulmuştur.
Sunulan yöntemde, en az optimize edilecek malzeme özelliği kadar deneysel veriye ihtiyaç vardır. Sayısal deneylerimizde beklenildiği gibi deney verisi sayısının artmasıyla yakınsamanın daha az iterasyonda gerçekleştiğini görülmüştür. Burada deney verisinin alındığı nokta ve zaman önemlidir. Örneğin, yanal kısıtlı sıkıştırma testinde deformasyon dokunun piston ile temas yüzeyinde başlar ve yavaş yavaş derinlere doğru difüze olur. $\mathrm{Bu}$ yüzden deneyin başladığı ilk anlarda yüzeye yakın noktalarda hassasiyet yüksek daha derinlerde ise düşüktür.

Kıkırdağın belli deneysel konfigürasyonları için ilgili diferansiyel denklemlerin analitik çözümü mevcuttur. Batırma adıverilen bir test için türetilen analitik çözüm, tersinerek malzeme özelliklerini belirlemede de kullanılabilmektedir [13]. Fakat, analitik çözümün mevcut olmadığı gelişigüzel bir deney geometrisi yardımıyla malzeme özelliklerini belirleme ancak bu çalışmada anlatılan yöntemle mümkündür. Benzer şekilde, dokunun doğrusal olmayan biçimde davrandığ (ki in vivo şartlarda bu gerçekleşir [14]) durumlarda da analitik çözüm mevcut değildir. Dolayısıyla, katı fazın hiperelastik özellikleri ve geçirgenliğin deformasyona olan bağımlılı̆̆ı sadece SEY optimizasyonu ile belirlenebilir.

İki fazlı dokuların malzeme özelliklerindeki homojen olmama durumu da bu dokuların işlevleri açısından önem arz etmektedir. Özelde, kıkırdağın malzeme sabitleri doku derinliği boyunca değişir $[15,16]$. Bu değişimi sayısallaştırmak da ancak bu çalışmada tarif edilen SEY optimizasyonu ile mümkündür.

\section{KAYNAKLAR}

1. Ün, M. K., 2007. Yumuşak Dokuların Mekaniği: Kıkırdak Menisküs, Tendon ve Bağ Dokuları, Kas-İskelet Sistemi Biyomekaniği, Editörler Akçalı İ.D., Gülşen M., Ün K., Rekmay Matbaacilik, Adana, 1, 251-324.

2. Pearle, A.D., Warren, R.F., Rodeo, S.A., 2005. Basic Science of Articular Cartilage and Osteoarthritis, Clinics in Sports Medicine, 24, $1-12$. 
3. Makris, E.A., Gomoll, A.H., Malizos, K.N., Hu, J.C., Athnasiou, K.A., 2015. Repair and Tissue Engineering Techniques for Articular Cartilage, Nature Reviews Rheumatology, 11, 21-34.

4. Mow, V.C., Gu, W.Y, Chen, F.H., 2005. Structure and Function of Articular Cartilage and Meniscus, Basic Orthopaedic Biomechanics and Mechano-Biology, Editörler Mow V.C., Huiskes R., LWW Publishing, Philadelphia.

5. Mow V.C., Kuei, S.C., Lai, W.M., Armstrong, C.G., 1980. Biphasic Creep and Stress Relaxation of Articular Cartilage in Compression: Theory and Experiments, Journal of Biomechanical Engineering, 102, 73-84.

6. Oomens, C.W.J., Van Campen, D.H., Grootenboer, H.J., 1987. A Mixture Approach to the Mechanics of Skin, Journal of Biomechanics, 20, 877-885.

7. Mendis, K.K., Stalnaker, R.L., Advani, S.H., 1995. A Constitutive Relationship for Large Deformation Finite Element Modeling of Brain Tissue, Journal of Biomechanical Engineering, 117, 279-285.

8. Simon, B.R., Wu, J.S.S., Carlton, M.W., France, E.P., Evans, J.H., Kazarian, L.E., 1985. Structural Models for Human Spinal Motion Segments Based on a Poroelastic View of the Intervertebral Disk., 1985. Journal of Biomechanical Engineering, 107, 327-335.

9. Simon, B.R., Kaufmann, M.V., McAfee, M.A., Baldwin, A.L., 1998. Porohyperelastic Finite Element Analysis of Large Arteries Using ABAQUS, Journal of Biomechanical Engineering, 120, 296-298.

10. Ün, M.K., 2002. A Penetration-Based Finite Element Method for Hyperelastic ThreeDimensional Biphasic Tissues in Contact, Doktora Tezi, Rensselaer Polytechnic Institute.

11. Almeida, E.S., Spilker, R.L., 1997. Mixed and Penalty Finite Element Models for the Nonlinear Behavior of Biphasic Soft Tissues in Finite Deformation: Part I-Alternate Formulations, Computer Methods in Biomechanical. and Biomedical Engineering, 1, 25-46.

12. Ün, K., Spilker R. L., 2007. A PenetrationBased Finite Element Method for Hyperelastic 3D Biphasic Tissues in contact: Part II-Finite
Element Simulations, Journal of Biomechanical Engineering, 128, 934-942.

13. Mak, A.F., Lai, W.M., Mow, V.C., 1987. Biphasic Indentation of Articular Cartilage: Part I, Theoretical Analysis, Journal of Biomechanics, 20, 703-714.

14. Holmes, M., Mow, V., 1990. The Nonlinear Characteristics of Soft Gels and Hydrated Connective Tissues in Ultrafiltration, Journal of Biomechanics, 23, 1145-1156.

15. Gao, L.L., Zhang, C.Q., Dong, L.M., Jia, Y.W., 2012. Description of Depth-Dependent Nonlinear Viscoelastic Behavior for Articular Cartilage in Unconfined Compression. Materials Science and Engineering: 32, 119-125.

16. Motavalli, M., Akkus, O., Mansour, J. M., 2014. Depth-dependent Shear Behavior of Bovine Articular Cartilage: Relationship to Structure. Journal of Anatomy, 225, 519-526. 